\title{
CAPÍTULO 54: PERFIL POPULACIONAL E CONHECIMENTO ACERCA DA FOME OCULTA E BIOFORTIFICAÇÃO DE ALIMENTOS
}

\section{CHAPTER 54: POPULATION PROFILE AND KNOWLEDGE ABOUT HIDDLE HUNGER AND FOOD BIOFORTIFICATION}

Maria Juliana Simplício de Souza ${ }^{1}$; Carina Raissa Rocha Oliveira da Cunha ${ }^{2}$; Amanda Priscila da Silva ${ }^{3}$; Raquel Maria da Silva ${ }^{4}$; Álvaro Carlos Gonçalves Neto ${ }^{5}$

\begin{abstract}
Resumo
A fome oculta é uma situação de risco a saúde humana que ocorre no mundo todo, principalmente em regiões e países menos desenvolvidos. A população mais pobre é a que mais vem sendo afetada pela fome oculta, isto porque essa população se alimenta com maior frequência de alimentos com alta densidade energética, ricos em açúcares e gorduras, mas de baixo valor nutritivo. Nesse cenário, observa-se a importância da biofortificação de alimentos para uma melhor alimentação. Apesar de ser um assunto alarmante e de grande importância, esses assuntos são ainda pouco abordados e divulgados pela mídia. Por isso, tendo em vista que a fome oculta ocorre devido à deficiências nutricionais, a mesma pode provocar doenças, aumentar risco de infecções e diminuir a qualidade de vida. Este artigo teve como objetivo realizar a investigação do perfil da população, avaliar o entendimento/conhecimento da mesma sobre a fome oculta e a biofortificação de alimentos e relacionarmos essas questões. Para isso foi desenvolvido questionário no Google Forms - serviço gratuito utilizado para criação de formulários online - contendo um total de 14 perguntas com questionamentos sobre $\mathrm{o}$ conhecimento da população acerca do tema abordado e perguntas de cunho pessoal. $\mathrm{O}$ questionário foi disponibilizado através de link remoto, sendo aplicado entre os dias 14 a 25 de julho de 2020. No total, foram obtidas 121 respostas onde os gráficos foram tabulados, agrupados e apresentados em gráficos/tabelas confeccionadas no excel. A maior parte dos pesquisados $(60,3 \%)$ foram do sexo feminino, com idade entre 18 e 25 anos e nível superior incompleto. A maior parte da população avaliada não possuía conhecimento algum sobre a biofortificação de alimentos $(72,7 \%)$ e a fome oculta $(83,5 \%)$, alegando ainda nunca terem ouvido estes termos. Apesar das diversas formas de comunicação e acesso à informação disponíveis atualmente como a internet, considerada segundo meio de comunicação mais utilizada, ainda é possível ver o quão é difícil o acesso à informação sobre a biofortificação e fome oculta pela população.
\end{abstract}

Palavras-Chave: Alimentos, nutrição, pesquisa exploratória. ${ }^{1}$

11 Graduanda do curso de Agronomia, integrante do Programa de Educação Tutorial-PET Agronomia, Universidade Federal Rural de Pernambuco - UFRPE. E-mail: julianasimplicio92@gmail.com

2 Graduanda do curso de Agronomia, integrante do Programa de Educação Tutorial-PET Agronomia, Universidade Federal Rural de Pernambuco - UFRPE. E-mail: carinaraissa1998@ hotmail.com

${ }^{3}$ Graduanda do curso de Agronomia, integrante do Programa de Educação Tutorial-PET Agronomia, Universidade Federal Rural de Pernambuco - UFRPE. E-mail: a.prisciila@ hotmail.com

${ }^{4}$ Mestranda do Programa de Pós-Graduação em Produção Agrícola (PPGPA), bolsista da Fundação de Amparo à Ciência e Tecnologia do Estado de Pernambuco (FACEPE); Universidade Federal do Agreste de Pernambuco- UFAPE. E-mail: raquel.maria18@hotmail.com

5 Doutor em Agronomia (Fitotecnia), Universidade Federal de Lavras - UFLA. E-mail: alvarocgneto@gmail.com 


\begin{abstract}
Hidden hunger is a situation of risk to human health that occurs worldwide, especially in less developed regions and countries. The poorest population is the one that has been most affected by hidden hunger, this because this population eats more frequently of foods with high energy density, rich in sugars and fats, but of low nutritional value. In this scenario, the importance of food biofortification for better nutrition is observed. Despite being an alarming and very important issue, these issues are still rarely addressed and disseminated by the media. Therefore, in view of the fact that hidden hunger occurs due to nutritional deficiencies, it can cause diseases, increase the risk of infections and decrease the quality of life. This article aimed to investigate the profile of the population, evaluate their understanding / knowledge about hidden hunger and the biofortification of food and relate these issues. For this purpose, a questionnaire was developed on Google Forms - a free service used to create online forms - containing a total of 14 questions with questions about the knowledge of the population about the topic addressed and questions of a personal nature. The questionnaire was made available via remote link, being applied between July 14th to 25th, 2020. In total, 121 responses were obtained where the graphs were tabulated, grouped and presented in graphs / tables made in excel. Most of the respondents $(60.3 \%)$ were female, aged between 18 and 25 years old and with incomplete higher education. Most of the evaluated population had no knowledge about food biofortification $(72.7 \%)$ and hidden hunger $(83.5 \%)$, claiming they had never heard of these terms. Despite the various forms of communication and access to information currently available, such as the internet, considered the second most used means of communication, it is still possible to see how difficult it is to access information about biofortification and hidden hunger by the population.
\end{abstract}

Keywords: Food, nutrition, exploratory research.

\title{
Introdução
}

A fome oculta é algo que acomete pessoas do mundo inteiro, independente de classe social. Trata-se de uma deficiência nutricional geralmente causada por alimentação incompleta e inadequada, de alto teor calórico e baixo teor de nutrientes. Essa questão torna-se mais complexa em regiões mais pobres, menos desenvolvidas, com agravante para crianças em pré-escola, gestantes, lactantes e idosos. O fator mais alarmante se dá pelo fato desse distúrbio alimentar ser silencioso, ou seja, imperceptível no organismo inicialmente (SIQUEIRA et al, 2020).

Vilas Boas (2016) afirma que a fome oculta acontece quando indivíduos possuem dietas inadequadas, no que tange o aporta a nutrientes, o que acaba acarretando em problemas de saúde e diminuição na qualidade de vida, o que gera para essas pessoas diversas enfermidades associadas a essa sub alimentação.

As principais vitaminas e minerais que se apresentam de forma insatisfatória na alimentação são: pró vitamina A, ferro e zinco, que geralmente ocorrem de forma combinada, principalmente no que se diz respeito ao ferro e zinco (BESSA, 2019). Algumas doenças causadas pela falta dessas vitaminas e sais minerais são: 
aumento do risco de infecções e cegueira noturna (pró vitamina A), podendo chegar à cegueira parcial ou total, anemia e atraso do desenvolvimento fetal (ferro), diarreia crônica e redução da imunidade (zinco), entre outros.

Os dados acerca da fome oculta são alarmantes, ela é responsável por debilitar mais de 2 milhões de pessoas em todo o mundo. $48 \%$ das crianças no mundo com menos de cinco anosde idade apresentam anemia (deficiência de ferro) e 30\% possuem deficiência em vitamina A. No Brasil, os números também são altos, 55\% das crianças com menos de cinco anos de idade apresentam deficiência de ferro e $13 \%$ de vitamina $\mathrm{A}$ (BioFORT, 2020).

Diante dessa problemática, surge a biofortificação de alimentos. Os estudos sobre o tema em questão tiveram início nos Estados Unidos em 1990, com Howarth Bouis, economista do Instituto Internacional de Pesquisa em Políticas Alimentares (IFPRI). Bouis começou a questionar se as próprias plantas não poderiam fazer o trabalho de combater a fome oculta e 10 anos depois ele fundava o programa HarvestPlus, um programa internacional que visa dar impulso e coordenar ações de biofortificação de alimentos no mundo (SILVA, 2018).

No Brasil, a biofortificação de alimentos é conduzida pela rede BioFORT, coordenada pela Embrapa. A rede reúne uma gama de mais de 150 pesquisadores e mais de 14 estados brasileiros, sempre priorizando regiões com baixos Índices de Desenvolvimento Humano (IDH), tornando o país destaque no mundo no que se diz respeito a biofortificação, pois é o único que trabalha com oito culturas simultaneamente, são elas: arroz, feijão, feijão-caupi e trigo (maiores teores de ferro e zinco); mandioca, milho, abóbora e batata-doce (maiores teores de vitamina A). Esses alimentos foram escolhidos tendo como critério principal a dieta comum dessas comunidades, ou seja, alimentos que já faziam parte de sua alimentação, dessa forma esses indivíduos não seriam obrigados a mudar o seu cardápio usual e não teriam ressalvas em receber esses alimentos (SILVA, 2018).

Os dados acerca da fome oculta são alarmantes, ela é responsável por debilitar mais de 2 milhões de pessoas em todo o mundo. $48 \%$ das crianças no mundo com menos de cinco anosde idade apresentam anemia (deficiência de ferro) e 30\% possuem deficiência em vitamina A. No Brasil, os números também são altos, endo $55 \%$ das crianças com menos de cinco anos de idade apresentando deficiências de ferro e $13 \%$ com deficiência de vitamina A (BioFORT, 2020). 
Tendo em vista o impacto desse problema na vida de várias pessoas ao redor do globo, o processo de biofortificação configura um esforço para a melhora do estado nutricional e promoção de alimentação saudável, diversificada em nutrientes, como a fortificação e a suplementação. Ela se configura como um complemento para reforçar outras alternativas de alimentação rica e saudável, como a fortificação e a suplementação. Além disso, a disseminação de conhecimentos técnico-científicos, experiências de produtores com o cultivo de alimentos biofortificados e divulgação para o público em geral faz com que a população aumente sua atenção sobre o consumo de alimentos e aspectos relacionados a nutrição, bem como anos que são levados em pesquisas e nas etapas para obtenção dos alimentos biofortificados sejam prestigiados e deem um bom resultado (BioFORT, 2020).

Sendo assim, este artigo teve como objetivo investigar o perfil, avaliar o entendimento/conhecimento de parte da população sobre a fome oculta e a biofortificação de alimentos e relacionar essas questões.

\section{Material e métodos}

O caminho metodológico utilizado neste trabalho foi um estudo descritivo de natureza quantitativa, sendo uma pesquisa de caráter exploratório. Como ferramenta para coleta de dados foi aplicado um questionário contendo 14 (catorze) perguntas, de forma remota. A plataforma eletrônica online utilizada para criação do questionário foi o Google Forms, o mesmo quantificou os dados e gerou os gráficos . Após a criação, foi gerado um link de acesso ao questionário. Este link foi divulgado e compartilhado em aplicativos de conversa em grupo, individual e redes sociais.

O início do compartilhamento se deu no dia 14 de julho de 2020 e foi encerrado em 25 de julho 2020. Foi utilizado o método de estatística descritiva para inferência dos resultados, visto que a mesma realiza uma descrição e sistematização dos dados amostrais, podendo ser expressa em tabelas e figuras gráficas.

\section{Resultados e Discussão}

Do público entrevistado, as mulheres representaram 60,3\%, como mostra a Figura 1. Em seguida, tivemos o sexo masculino com $38 \%$ das respostas e outros com $1,7 \%$. Atualmente, segundo Instituto Brasileiro de Geografia e Estatística (IBGE, 2019), o Brasil possui cerca 211,9 milhões de habitantes, sendo 51,8\% da população composta por mulheres e $48,2 \%$ da população representada por homens. 
Com a inserção cada vez maior da mulher no mercado de trabalho, o consumo de lanches e alimentos ultraprocessados pode ser uma tendência pela falta de tempo e praticidade, deixando de lado alimentos que exigem mais tempo de cozimento e provavelmente mais saudáveis. Os diferenciais de morbimortalidade constatados entre homens e mulheres resultam, em grande parte, de diferenças do estilo de vida e dos comportamentos relacionados à saúde. Pesquisas nacionais que utilizam marcadores de consumo alimentar saudável e não saudável apontam que comparados às mulheres, os homens apresentam prevalências mais elevadas de ingestão de sal, de refrigerantes e de carnes com excesso de gordura, bem como menor ingestão de frutas e hortaliças (ASSUMPÇÃO et al., 2017).

Figura 1. Sexo da população avaliada.

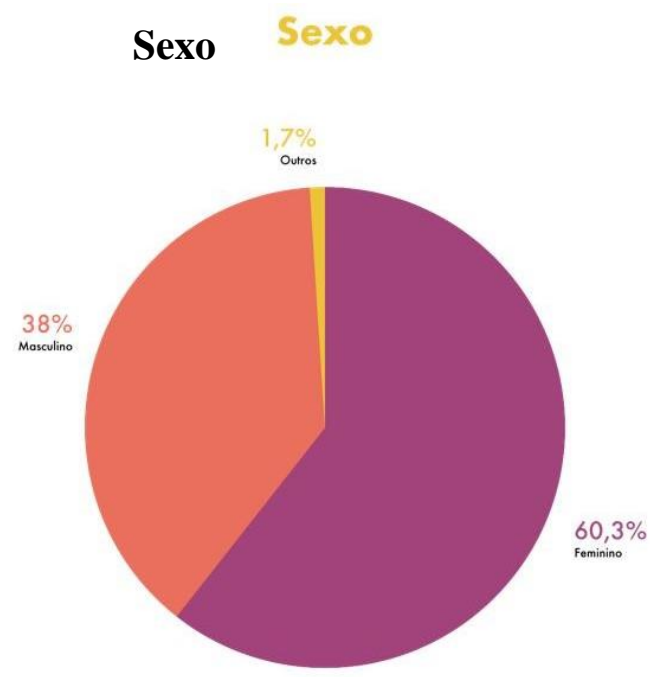

Fonte: Própria (2020).

Quanto a faixa etária dos entrevistados, 38\% eram pessoas com idade de 18-25 anos, a idade de 26-35 anos com 29,8\% das respostas, a idade de $36-45$ anos com $12,4 \%$, a idade de pessoas com mais de 45 anos com 10,7\% e menores de 18 anos representando 9,1\% (Figura 2). Segundo Delmondes (2016) a qualidade da alimentação tende a melhorar com o aumento da idade e da escolaridade. Entretanto, é sabido que pessoas mais velhas tendem a usar menos tecnologias do que os jovens entre 18-25 anos, o que explica a ampla adesão de respostas na presente pesquisa. 
Figura 2. Faixa etária da população entrevistada

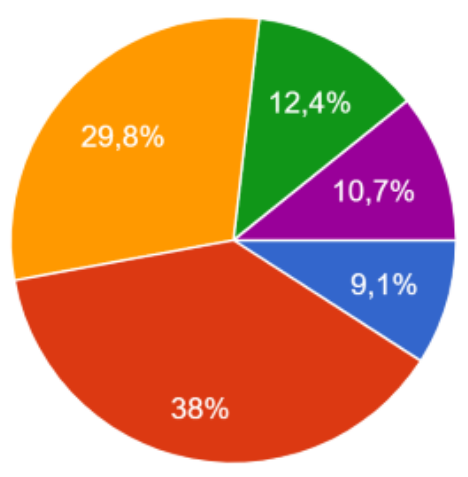

Menor que 18 anos
$18-25$ anos
$26-35$ anos
$36-45$ anos
Maior que 45 anos

Fonte: Própria (2020).

Tratando-se da escolaridade do público atingido, 36,4\% possui ensino superior incompleto, $27,3 \%$, possuindo ensino superior completo, $16,5 \%$ com ensino médio completo, 6,6\% com ensino médio incompleto, 6,6\% possuem ensino fundamental incompleto, $4,13 \%$ possuem fundamental completo e por fim $2,47 \%$ responderam outros (Figura 3). Uma pesquisa afirmou que pessoas mais escolarizadas ingerem mais grãos integrais, frutas, vegetais, leite e derivados, e também mais gordura saturada do que aquelas que tinham até sete anos de estudo, evidenciando que quanto maior a escolaridade, maior a preocupação com a alimentação (DELMONDES, 2016).

Figura 3. Nível de escolaridade da população avaliada.

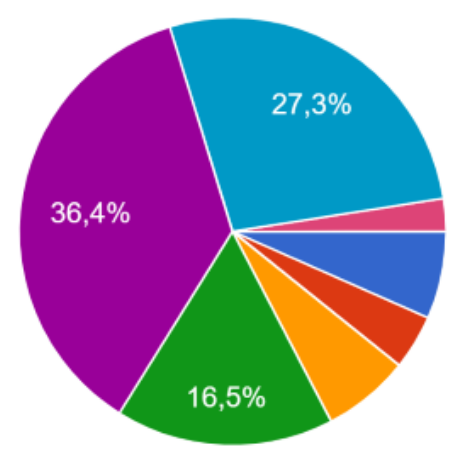

Ensino fundamental incompleto

- Ensino fundamental completo

Ensino médio incompleto

Ensino médio completo

- Ensino superior incompleto

Ensino superior completo

Outro

Fonte: Própria (2020).

Do universo investigado, 76,9\% residem em área urbana e 23,1\% afirmaram residir na zona rural (Figura 4). Mais da metade da população mundial vive em áreas urbanas, no Brasil chega a 80\%. E, é sabido que o Brasil é um país de dimensões continentais, com variações regionais significativas e um patrimônio culinário 
expresso em hábitos e receitas tradicionais. Porém, os processos de urbanização e industrialização desiguais parecem afetar de forma diferenciada os grupos populacionais e, provavelmente, as macrorregiões do país. De tal modo que, avaliar as diferenças no consumo alimentar dos brasileiros que vivem em áreas urbanas e rurais é importante, sobretudo pelo país apresentar contínuo e sistemático esforço para garantir o Direito Humano a Alimentação Adequada e Saudável e a soberania alimentar mediante a valorização e respeito à cultura alimentar.

Segundo tal trabalho, há diferenças no consumo alimentar, segundo marcadores de alimentação saudável e não saudável, entre adultos residentes nas áreas urbanas e rurais do Brasil, e macrorregiões. Brasileiros residentes nas áreas rurais têm maior chance de manter um padrão alimentar tradicional, com o consumo de alimentos minimamente processados, especialmente feijão; e menor consumo de alimentos ultraprocessados; apesar do menor consumo de frutas e hortaliças, e de peixes. (COSTA et al., 2020). Mas sabemos que a energia elétrica, bem como o acesso à Internet ainda são escassos na zona rural, o que dificulta a sua participação em pesquisas remotas.

Figura 4. Área de residência dos avaliados

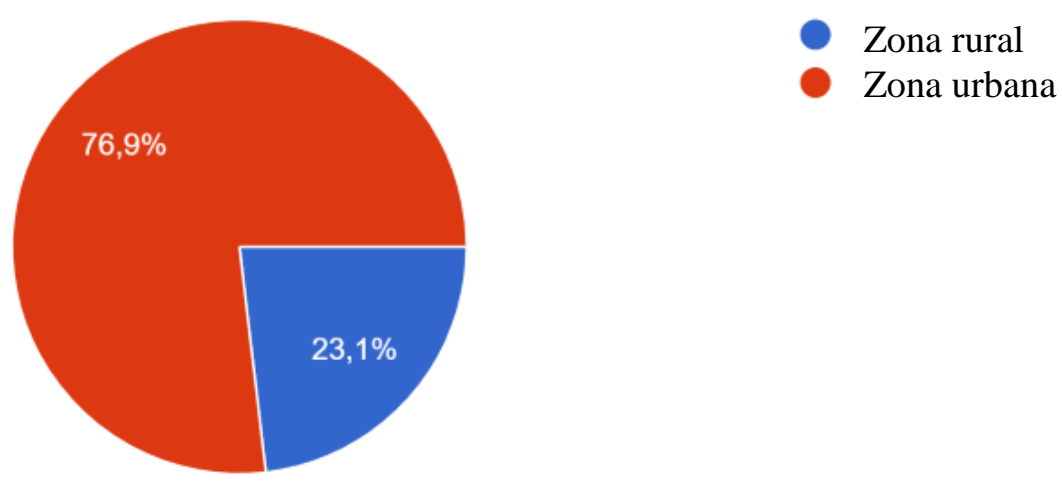

Fonte: Própria (2020).

83,5\% negaram já terem ouvido falar sobre a fome oculta, já 16,5\% afirmaram já terem ouvido (Figura 5).A professora do Instituto de Nutrição da Universidade Federal do Rio de Janeiro (UFRJ), Andréa Ramalho afirma que o combate à fome oculta tem apresentado resultados tímidos diante da grandeza do problema, que atinge até mesmo regiões consideradas fora do eixo tradicional da miséria no Brasil. O custo de não intervir adequadamente para superar as carências específicas é muito maior do que o custo de programas de intervenção. Mesmo assim não é raro que os setores envolvidos na busca de uma solução - universidades, governos, indústrias, mídia e população - falem 
SOUZA, M. J. S; CUNHA, C. R. R. O; SILVA, A, P; SILVA, R. M; GONÇALVES NETO, Á. C.

linguagens diferentes. Além disso, afirma que precisamos de interfaces entre esses setores para permitir que o conhecimento científico se traduza em ações e programas de intervenção nutricional de alcance social (ÉPOCA, 2015).

Figura 5. Conhecimento da população sobre a fome oculta.

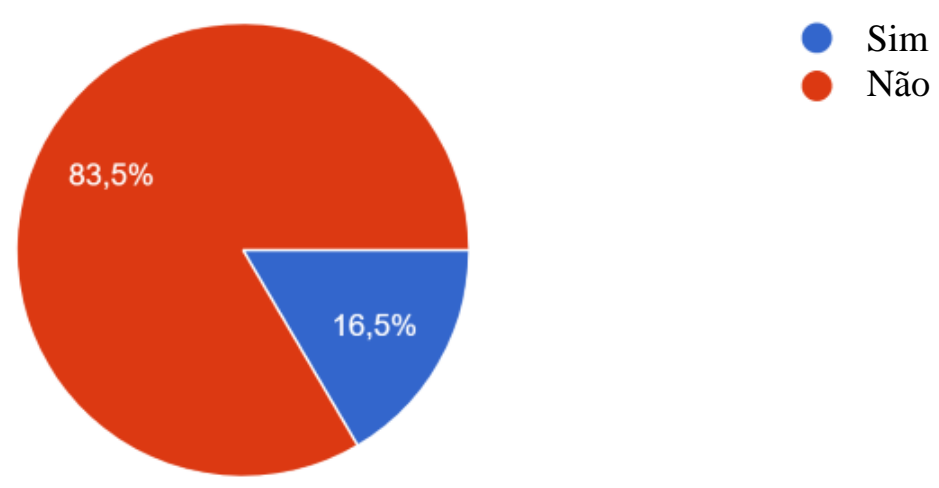

Fonte: Própria (2020).

Quando questionados se já tiveram conhecimento sobre algum caso de fome oculta, 86,8\% alegaram não conhecerem algum caso. Já 13,2\% alegam conhecer (Figura 6). A insegurança alimentar e nutricional no Brasil tem duas faces: uma associada à negação do direito ao acesso à alimentação necessária à vida; outra resultante da alimentação inadequada ou não saudável. Pessoas com excesso de peso ou obesidade são pessoas expostas ao consumo inadequado de alimentos. Na alimentação dos mais pobres, alimentos com alta densidade energética - açúcares, refrigerantes e alimentos com alto teor de gordura - vêm substituindo alimentos tradicionais mais saudáveis (PINHEIRO, CARVALHO, 2010).

Por não apresentar sinais clínicos de carência, que são característicos das manifestações finais do quadro de ausência de vitaminas e minerais, a fome oculta se instala de forma imperceptível e silenciosa. Porém, mesmo que não evolua para os estágios terminais da deficiência, já causa prejuízos à saúde, podendo comprometer várias etapas do processo metabólico, com alterações no sistema imunológico, nas defesas antioxidantes e no desenvolvimento físico e mental. A deficiência é fator predisponente/agravante de diversas doenças crônicas, como doenças cardiovasculares, hipertensão arterial, diabetes mellitus, dislipidemia, obesidade, alguns tipos de câncer e osteoporose, entre outras (ÉPOCA, 2015) 
Figura 6. Conhecimento de algum caso de fome oculta.

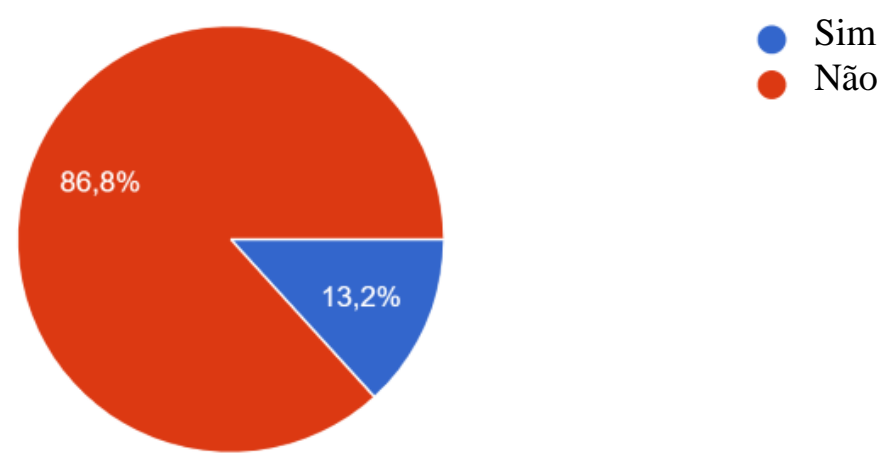

Fonte: Própria (2020).

$66,9 \%$ dos entrevistados afirmaram que não ouviram falar sobre a biofortificação de alimentos e 33,1\% afirmam que já tinham ouvido falar (Figura 7). Desde os anos 1940, Josué de Castro ampliara o reconhecimento das distintas formas e expressões da fome, e denunciava a monocultura como uma causa estrutural da alimentação e da fome oculta. No entanto, muitas instituições e iniciativas insistem em soluções que não interferem sobre as causas do problema, quando sim apenas sobre os desfechos (GOMES et al., 2016).

Figura 7. Já ter ouvido falar e conhecimento da população sobre biofortificação de alimentos

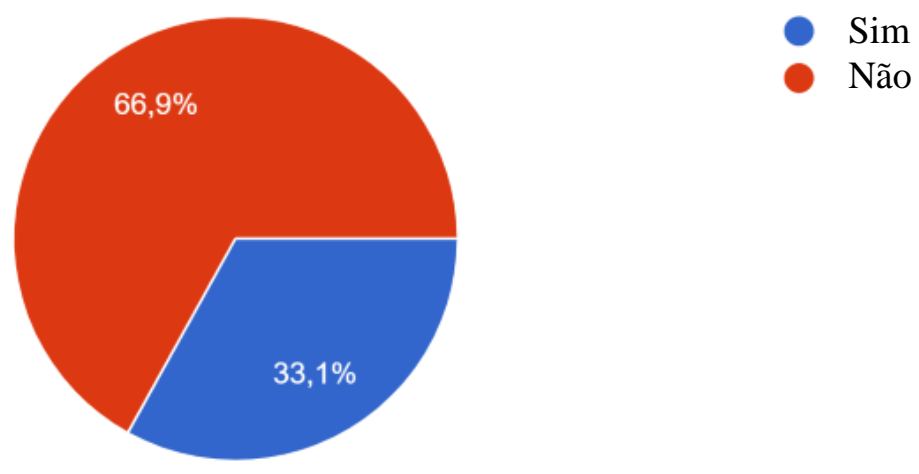

Fonte: Própria (2020).

Questionando sobre se as pessoas sabiam o que é a biofortificação de alimentos, a resposta majoritária foi afirmando que não sabiam o que é, 72,7\%. Em seguida, tivemos $27,3 \%$ das respostas afirmando que sabiam (Figura 8). 
Figura 8. Conhecimento da população sobre biofortificação de alimentos

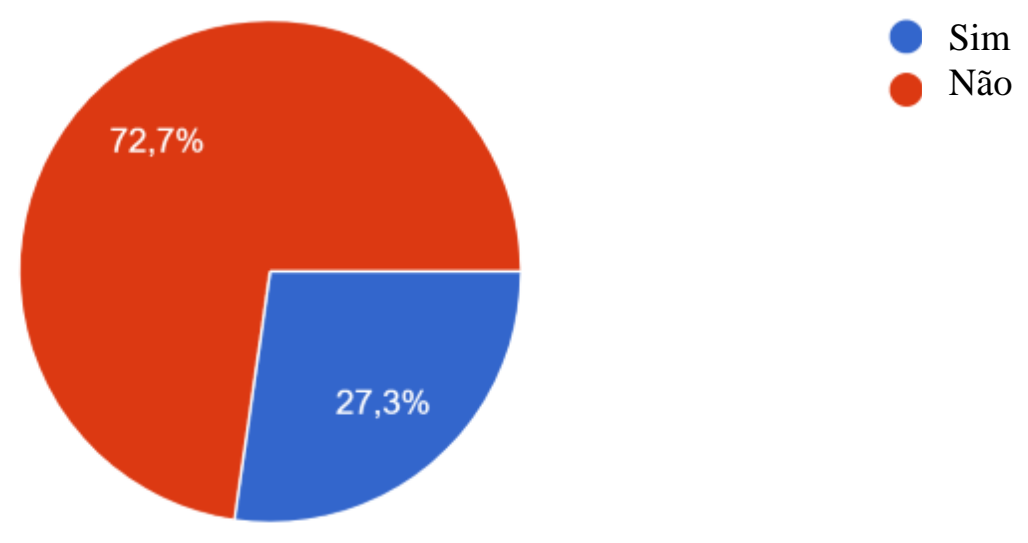

Fonte: Própria (2020).

Das pessoas que afirmaram que sabiam o que é a biofortificação de alimentos, a resposta majoritária foi afirmando que souberam através da Internet 57,8\%. Em seguida, tivemos $20 \%$ das respostas afirmando que conheceram através de amigos, $6,7 \%$ jornais como dados principais (Figura 9). A internet é o segundo meio de comunicação usado mais frequentemente pelos brasileiros, atrás da televisão e à frente do rádio, segundo a primeira edição da Pesquisa Brasileira de Mídia 2014 - Hábitos de Consumo de Mídia pela População Brasileira (G1, 2014).

Figura 9. Métodos pelo qual a população tomou conhecimento da biofortificação de alimentos.
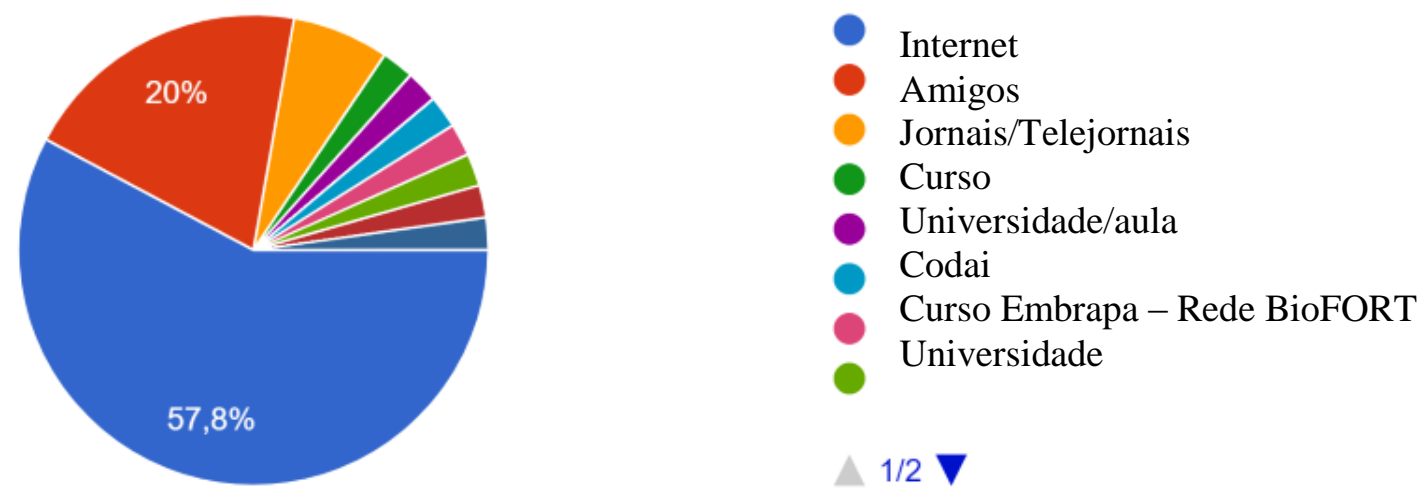

Fonte: Própria (2020).

Quando perguntados sobre qual o sexo tinha mais interesse por esse assunto, $73,3 \%$ afirmaram que eram as mulheres e $26,7 \%$ afirmaram que eram os homens (Figura $10)$. 
SOUZA, M. J. S; CUNHA, C. R. R. O; SILVA, A, P; SILVA, R. M; GONÇALVES NETO, Á. C.

Figura 10. Interessados pela biofortificação de alimentos.
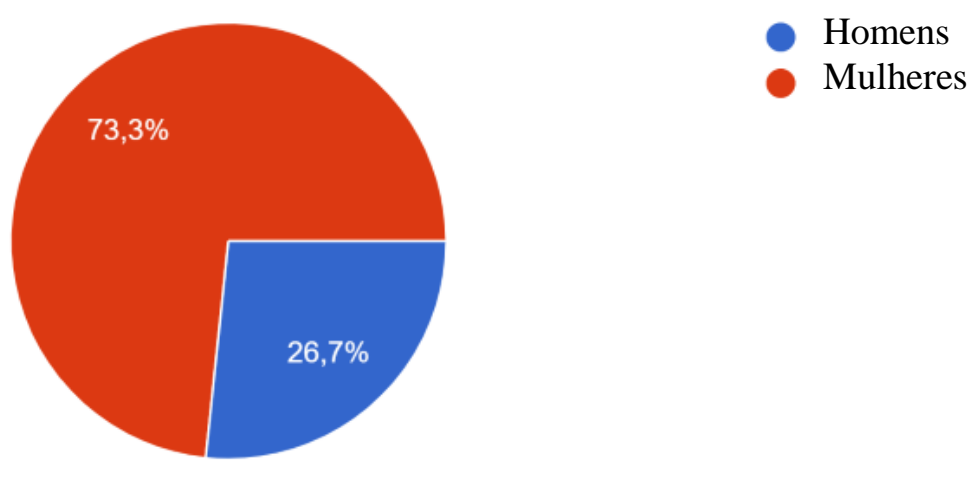

Fonte: Própria (2020).

E quando perguntados sobre o conhecimento de quais alimentos eram biofortificados, $77,7 \%$ negaram saber e $22,3 \%$ afirmaram saber (Figura 11).

Figura 11. Conhecimento da população sobre as plantas alimentícias biofortificadas atualmente.

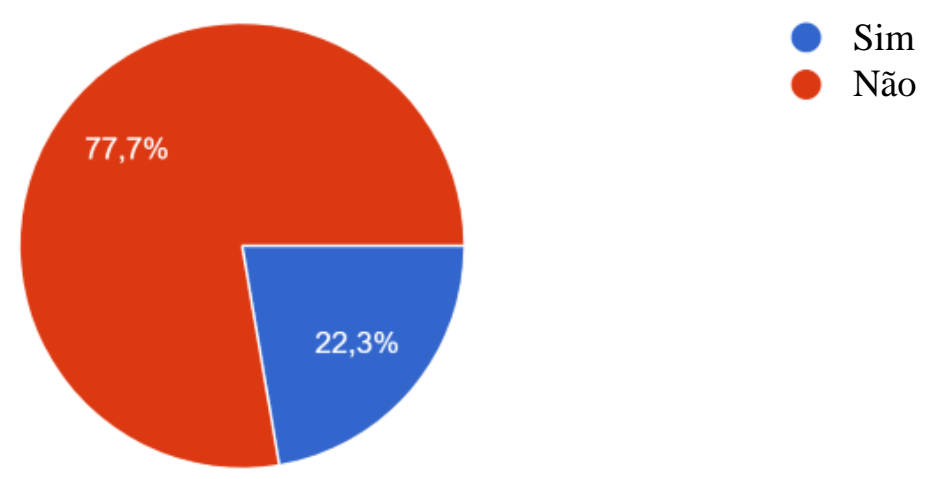

Fonte: Própria (2020).

Ao observar se as pessoas já consumiram

alimentos biofortificados, $82,6 \%$ afirmaram não saber, $14 \%$ afirmaram que já consumiram e 3,3\% disseram que não consumiram (Figura 12). 
Figura 12. Conhecimento da população acerca de seu próprio consumo de alimentos biofortificados.

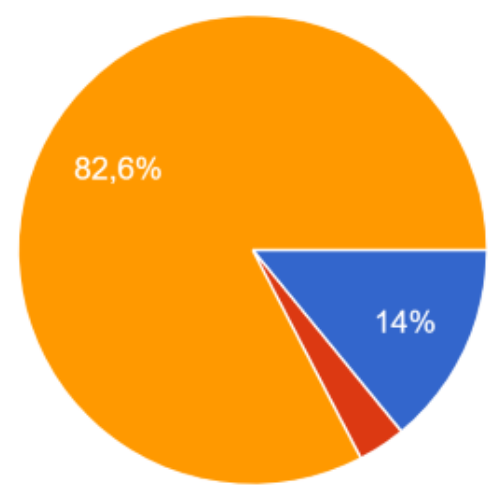
Sim
- Não
Não sei

Fonte: Própria (2020).

$\mathrm{Na}$ pesquisa, $82,6 \%$ afirmaram que não sabiam onde obter alimentos biofortificados, enquanto 17,4\% afirmaram que sabiam onde encontrar (Figura 13).

Figura 13. Conhecimento da população acerca de locais de obtenção de alimentos biofortificados.

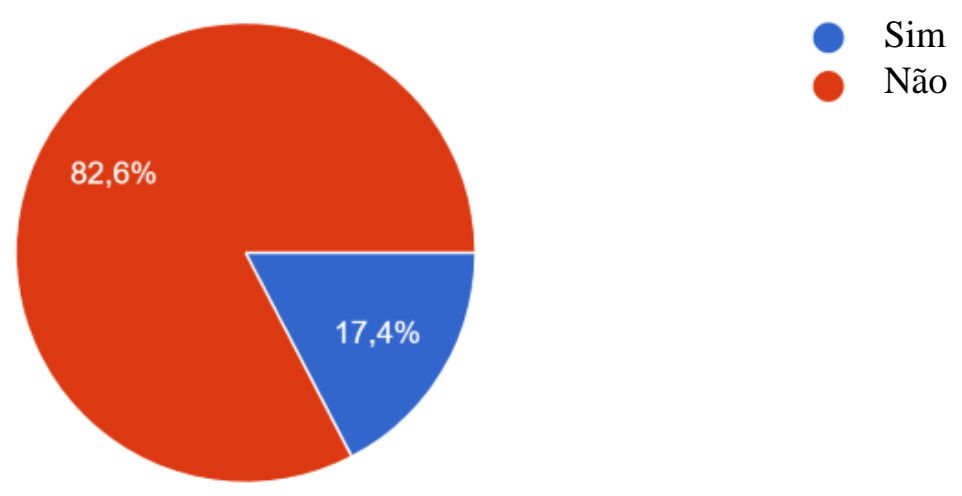

Fonte: Própria (2020).

Quando questionados acerca de quantas plantas alimentícias estavam sendo biofortificadas no Brasil, 20,7\% responderam que 10 culturas estavam sendo biofortificadas, $14 \%$ responderam que apenas 5 culturas, 11,6\% responderam que nenhuma cultura estava sendo biofortificada no país e 46,7\% responderam outros. Apenas $5,8 \%$ dos avaliados responderam o valor correto, 8 culturas. 
SOUZA, M. J. S; CUNHA, C. R. R. O; SILVA, A, P; SILVA, R. M; GONÇALVES NETO, Á. C.

Sobre o consumo de vitaminas e suplementos alimentares, 60,3\% afirmaram não consumir e 39,7\% afirmaram que consumiam (Figura 14).

Figura 14. Consumo pela população, de suplementos e vitaminas alimentares.

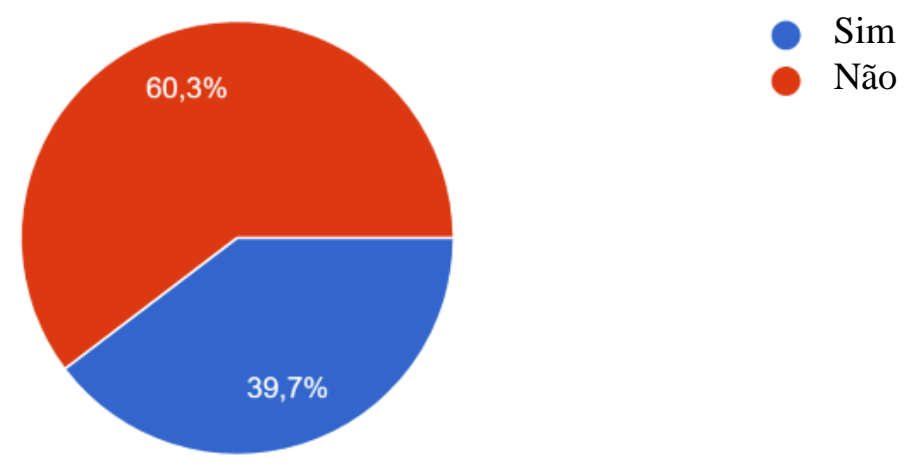

Fonte: Própria (2020).

Outra questão é o fato que a compra destes produtos não significa estar levando alimentos biofortificados para a mesa dos brasileiros; isto, porque o problema vem desde o início da cadeia produtiva, onde as sementes biofortificadas chegam sem nenhum controle às mãos dos agricultores familiares, estes, responsáveis pela maior parte da produção dos alimentos, como a mandioca e batata doce.

\section{Conclusões}

A pesquisa mostrou que grande parte da população ainda não tem conhecimento sobre o que se trata a fome oculta e a biofortificação de alimentos, muito embora esses assuntos venham sendo trabalhados no Brasil desde meados dos anos 2000. As pessoas que menos possuem conhecimento sobre o tema abordado são mulheres com idade entre 18 e 25 anos, com grau de escolaridade de ensino superior incompleto e residentes de área urbana.

Por mais que o Brasil esteja na posição de país destaque na produção de alimentos biofortificados, o mesmo não se destaca no fornecimento de informações sobre este assunto, deixando a população, em sua maior parte, sem conhecimento sobre este tipo de alimento.

\section{Referências}

ASSUMPÇÃO, D et al. Diferenças entre homens e mulheres na qualidade da dieta: estudo de base populacional em Campinas. Ciências e Saúde Coletiva. 22.2. fev. 2017. 
SOUZA, M. J. S; CUNHA, C. R. R. O; SILVA, A, P; SILVA, R. M; GONÇALVES NETO, Á. C.

Disponível em: <https://www.scielosp.org/article/csc/2017.v22n2/347-358/>. Acesso em 28 de jul. de 2020.

BESSA, F. Pesquisa da Embrapa busca aumentar teor de zinco de arroz no Maranhão. 2019. Disponível em: <https://www.grupocultivar.com.br/noticias/pesquisada-embrapa-busca-aumentar-teor-de-zinco-de-arroz-no-maranhao>. Acesso em: 27 julho 2020.

BIOFORT. Perguntas Frequentes. Disponível em: <https://biofort.com.br/perguntasfrequentes/>. Acesso em: 25 jul. 2020.

COSTA, D.V.P et al. Diferenças no consumo alimentar nas áreas urbanas e rurais do brasil: Pesquisa nacional de saúde. Ciência \& Saúde Coletiva. Disponível em: < http://www.cienciaesaudecoletiva.com.br/artigos/diferencas-no-consumo-alimentar-nasareas-urbanas-e-rurais-do-brasil-pesquisa-nacional-de-saude/17486> Acesso em 29 de julho de 2020.

\section{DELMONDES, C. Qualidade da dieta aumenta com idade e escolaridade, aponta pesquisa da FCM. 2016. Disponível em: <https://www.fcm.unicamp.br/fcm/noticias/2016/qualidade-da-dieta-aumenta-com- idade-e-escolaridade-aponta-pesquisa-da-fcm>. Acesso em 28 de julho de 2020.}

ÉPOCA. Fome oculta: um problema real. Redação prêmio Jovem Cientista. 15 de abril de 2015. Disponível em: <https://epoca.globo.com/vida/noticia/2015/04/fome-ocultaum-problema-real.html>. Acesso em: 28 de julho de 2020.

G1. Segundo meio de comunicação mais usado é internet, aponta pesquisa: $26 \%$ usam internet diariamente, e $65 \%$ veem TV todos os dias, indica Ibope. Governo encomendou pesquisa que revela hábitos de consumo de mídia, 2014. Disponível em: <http://g1.globo.com/economia/midia-e-marketing/noticia/2014/03/segundo-meio-decomunicacao-mais-usado-e-internet-aponta-pesquisa.html> Acesso em: 31 jul. 2020.

GOMES, F.S et al. Biofortificação: As controvérsias e as ameaças à soberania e segurança alimentar e nutricional. Disponível em: <https://br.boell.org/sites/default/files/biofortificacao_as-controversias-e-as-ameacas-asoberania-e-seguranca-alimentar-e-nutricional.pdf>. Acesso em 28 de jul de 2020.

BRASIL, Instituto brasileiro de geografia e estatística - IBGE, 2019. Disponível em <https://biblioteca.ibge.gov.br/visualizacao/livros/liv101707_informativo.pdf>. Acesso em: 30 de julho de 2020 .

PINHEIRO, A.R.O; CARVALHO, M.F.C.C. Transformando o problema da fome em questão alimentar e nutricional: uma crônica desigualdade social. Ciência \& Saúde Coletiva.15. 1.2010 .2 Jan. Disponível em: <https://www.scielo.br/scielo.php?script=sci_arttext\&pid=S1413 $81232010000100018 \& \operatorname{lng}=e n \& n r m=i s o>$. Acesso em: 27 de julho de 2020.

SILVA, C.S.M; ARAÚJO, C.R.M. Introdução à Biofortificação. Módulo II: Afinal, o que é biofortificação? 28 de julho de 2018. Disponível em: <https://ava.sede.embrapa.br/course/view.php?id=66>. Acesso em 29 de julho de 2020. 
SIQUEIRA, K.B et al. Custo benefício dos nutrientes dos alimentos consumidos no Brasil. Ciência \& Saúde Coletiva, 25 (3): 1129-1135, 2020. Disponível em: $<$ https://www.scielosp.org/article/csc/2020.v25n3/1129-1135/>. Acesso em 28 de julho de 2020.

VILAS BOAS, L. G. Fome oculta e seus liames como a economia, a política e a sociedade. GeoGraphos. Alicante, Grupo Interdisciplinario de Estudios Críticos y de América Latina de la Universidad de Alicante, v. 7, n. 90, p. 207-232, sept. 2016. Disponível em: < https://rua.ua.es/dspace/bitstream/10045/57425/1/Lucas_Guedes.pdf>. Acesso em: 14 maio 2018. 